\title{
Snow disposal in Moscow
}

\author{
Oleg Primin ${ }^{1 *}$ \\ ${ }^{1}$ Moscow State University of Civil Engineering, Yaroslavsky Highway, 26, Moscow, 129337, Russia
}

\begin{abstract}
The main principle of the strategy of the integrated improvement the functioning of a city of the northern region and its infrastructure in winter is a systematic solution to the problem of industrial disposal of snow mass in various parts of the city road network, removal and utilization of snow. The implementation of the strategy in the capital of Russia - the city of Moscow is based on the use of the General snow disposal scheme. In connection with the meteorological conditions that have changed in recent years in Moscow, i.e. increase in the height of the snow cover and extension of the roadway paving subject to cleaning, the use of advanced technologies of snow collection and disposal, new types of deicing agents, the aim of the research was updating the General snow disposal scheme in Moscow. As a method of its implementation, we used a statistical analysis of the formation in recent years of the volume and average annual depth of the snow cover in the city of Moscow, an estimation of the heat capacity of sewers and a heating network for the utilization of snow mass. The article presents the results of the implementation of the updated General snow disposal scheme, gives suggestions for snow removal in extreme snowfalls.
\end{abstract}

\section{Introduction}

Analysis of the location of large cities and megacities on the territory of our planet revealed the most important feature of the city of Moscow. There is no other metropolis on any continent that, with such a large population (more than 12 million people currently live in Moscow), would be located in similar geographic, climatic, geotechnical, and hydrological conditions. Almost all megacities or large cities are located significantly southward of the latitude of Moscow.

Therefore, snow removal from highways and sidewalks of the territory of cities in the northern regions including such a megalopolis as the city of Moscow, is a necessary condition for their normal functioning in the winter period $[1,2,3]$.

The problem of snow removal did not arise in a flash. Before the revolution in Moscow, by a special municipal decree, cleaning of roads and sidewalks was the responsibility of the owners of the respectively adjoined houses and grounds [4]. If no owners were available, the responsibilities were assumed by the territory manager.

It was required to clean the sidewalks from snow, break off the ice and sprinkle sand on the pedestrian areas daily before eight o'clock in the morning. Snow was collected in piles that were evacuated during the day, Figure 1.

\footnotetext{
*Corresponding author:tepper2007@yandex.ru
} 


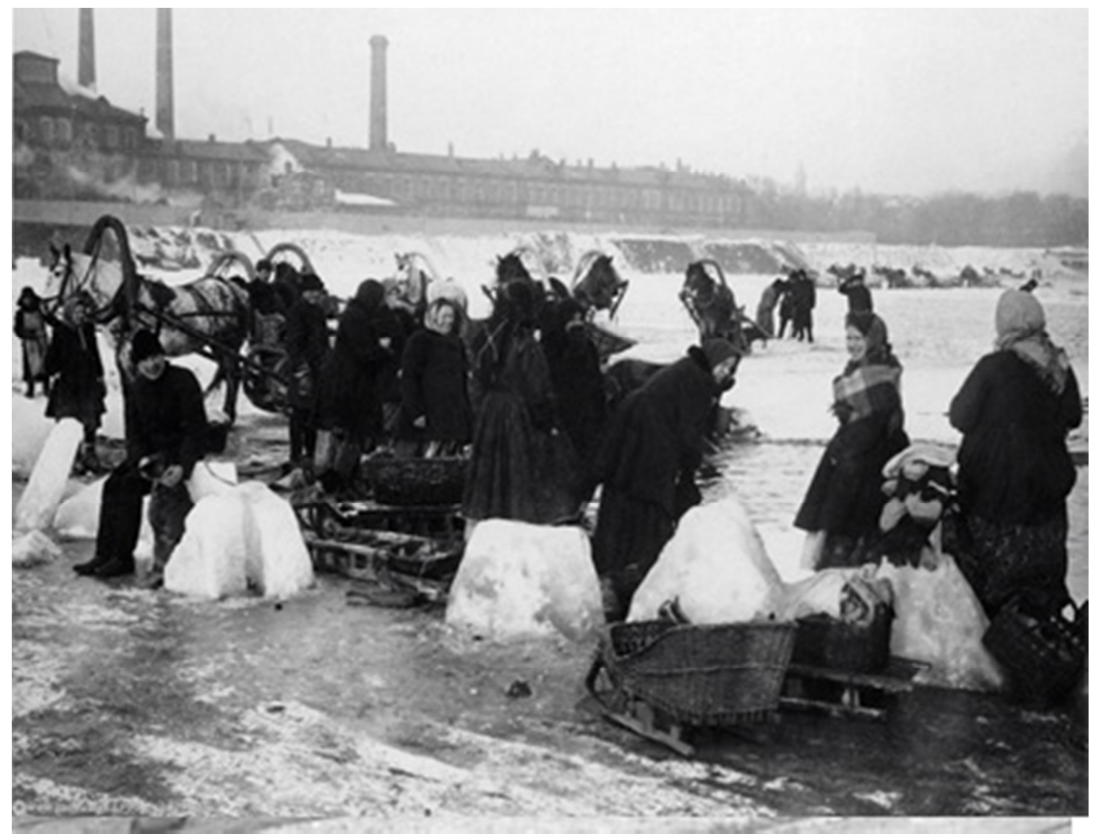

Fig. 1 Snow evacuation 120 years ago.

Snow and ice had to be removed from roofs quickly as and when necessary; the territory for stockpiling ice and snow was assigned annually by the city administration; the information on the snow collection sites was published in the newspapers. However, removing snow to "vacant lands and kitchen gardens" was not forbidden. The decree clearly stipulated taboos. It was strictly forbidden to dump dirty snow into rivers, ditches and ponds. It was forbidden to throw snow from the streets and sidewalks over fences and lattice screens, as well as to spread over the territory. Violators were subject to fines.

In Soviet times, the previously existing snow removal system in the city of Moscow was focused on dumping snow mass into open water bodies - the Moskva, Yauza, rivers and others. Fig. 2. [5, 6].

As shown by long-term observations, the bottom sediments of the Moskva River and small rivers of the city were polluted with highly concentrated anthropogenic pollutants, which negatively affected the environment. According to the calculations, from 1996 to 2000 about 350 thousand tons of deicing salt were used per month in the city [7].

The total amount of pollutants discharged into the rivers with polluted melt water amounted to about $60 \%$ of the total pollution discharges into the city water bodies. In some cases, the level of pollution of the snow discharged into the rivers exceeded the maximum permissible concentrations (MPCs) for oil products by 500-3000 times, for chlorides by 20100 times, and for salts of heavy metals - 500-2000 times. [8].

Alongside with the pollution of surface water bodies, natural snow melting and the use of deicing chemicals based on chlor-sodium compounds caused soil pollution on the territory of Moscow [9].

In the early 2000s, the Moscow government set the task of solving the problem of snow disposal by industrial methods eliminating the discharge of snow mass into the city water bodies and its removal to dry snow melting grounds. [10]. 


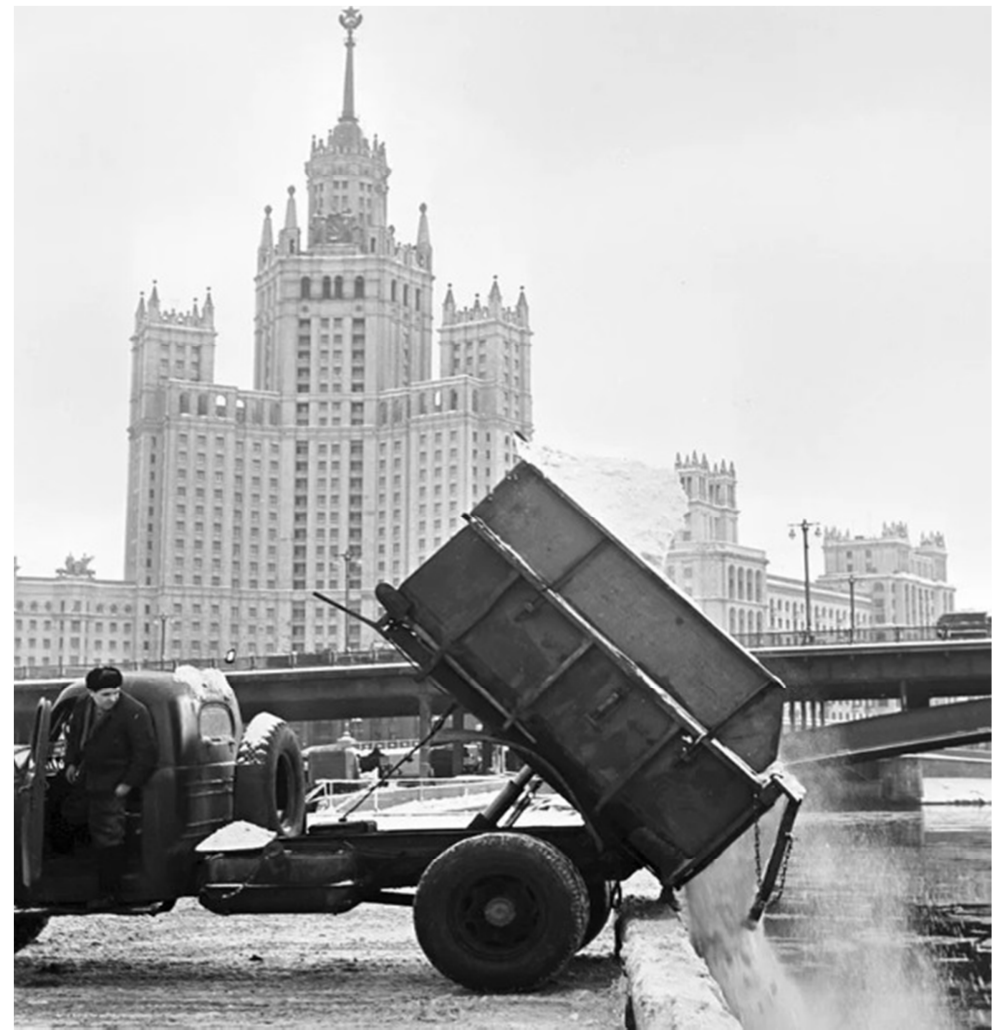

Fig. 2. Discharge of snow into the Moskva River (60-ies of the last century)

\section{Methods and materials}

Possible use of the municipal sanitation system for snow disposal has been considered since the construction of sewers capable of transporting and melting snow. It was found that the municipal sewer network had the largest surplus heat inside [11,12].

In the 50s of the last century, recommendations were developed on the use of sewers for snow disposal. The recommendations focused on the possible snow disposal into the manholes. However, the sewer network became heavily clogged, and at the end of the winter season considerable funds had to be spent on its cleaning. In addition, "snow plugs" formed in the sewers because of the improper arrangement of snow melting.

This led to the prohibition of discharging snow and ice melt water into the municipal sewer network. Nevertheless, even then, projects were proposed for the construction of fixed-site snow melting stations on sewers to use the heat of wastewater for processing large masses of snow with the protection from pollutants contained in snow.

In 1957-1958, in Moscow, snow disposal into the storm sewer gained widespread use. Then more than 30 snow-receiving chambers were built on the collection pipelines of underground rivers (the Neglinka, the Presnya, etc.). The experience of their operation showed the incorrect location of the chambers and, most importantly, the need for building expensive treatment facilities at the outlets of the pipelines into the watercourses.

In the mid-80s of the last century, Mosinzhproekt Institute developed a project of a snow-melting station on a gravity sewer. According to this project, 6 snow-melting stations had been built that operated until 2001. However, because of the deterioration of the quality of the brought in snow the capacity of the pollution accumulating tanks provided by the 
project designers was insufficient.

The tanks were quickly filled and pollutants were discharged further into the main sewer. Obviously, this situation was unacceptable for the operations department of the Moscow sanitation system [13].

The research on industrial snow disposal methods, the experience of the northern cities of the world (Canada, Finland, Sweden) made it possible to develop in 2002 a General snow disposal scheme in Moscow $[16,17,18]$. In the General scheme an approach to snow utilization was implemented by using low-grade heat from sewers and building a new type of snow-melting stations (SMS) that provided for complete abandoning environmentally hazardous dry snow dumping sites and snow dumping into the Moskva and Yauza Rivers.

\section{Results}

Currently, the solution to the problem of large-scale snow utilization in the city of Moscow has been improved to the stage of using the following industrial methods of snow disposal:

- fixed site snow-melting stations on the main sewers of the municipal sewer network (SMS);

- SMSs on the wash water lines of the thermal power plants;

- SMSs with the use of diesel fuel and gas;

- SMSs at the surface runoff wastewater treatment facilities;

- mobile snow-melting units, (MSMUs).

The total design capacity of all types of snow-melting stations at a snow density of 0.3 $\mathrm{t} / \mathrm{cu} . \mathrm{m}$ is $428,458 \mathrm{cu} \mathrm{m} /$ day.

This system provides for the disposal of 49.497 million $\mathrm{m}^{3}$ of snow in winter season. The bulk of snow is disposed of at the fixed-site SMSs built on the sewers, Fig. 3.

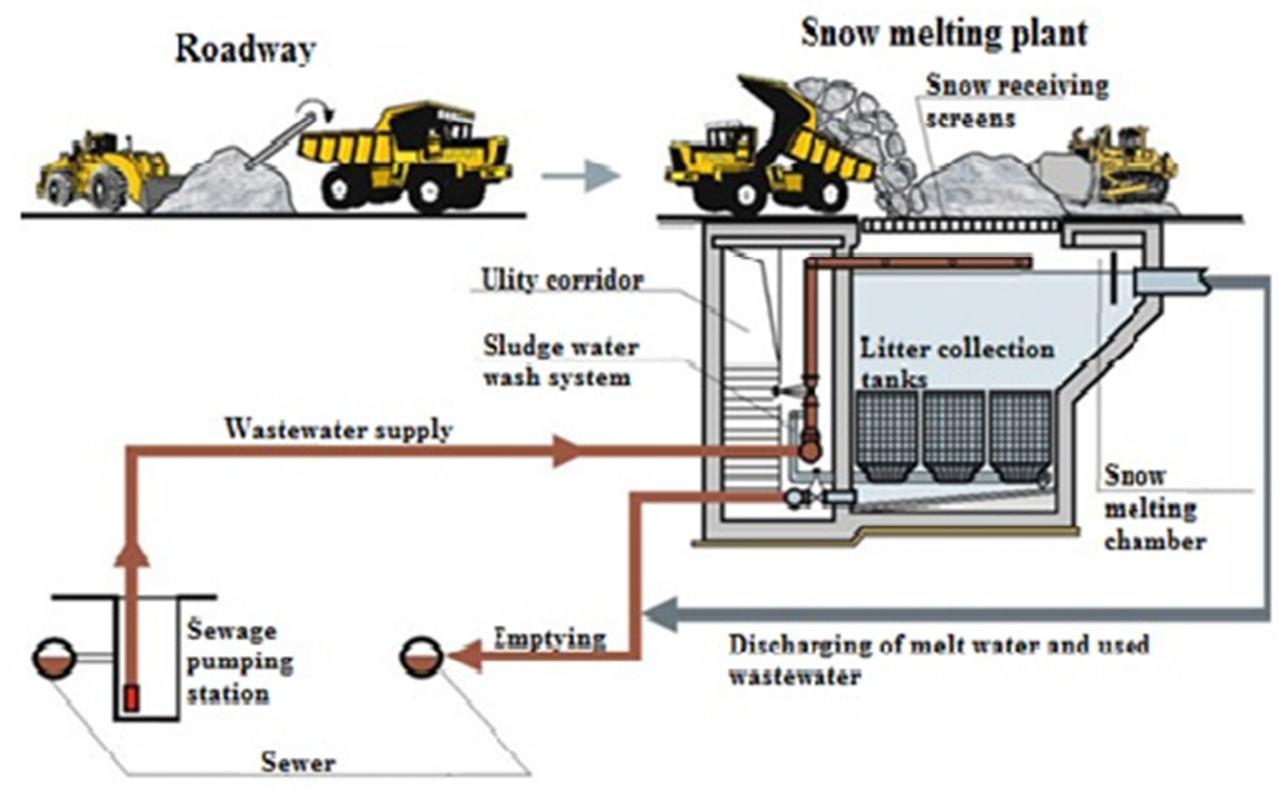

Fig.3. Snow utilization flow scheme at a snow-melting station built on a sewer.

Snow processing (melting) at the SMS is carried out by feeding wastewater from the municipal sewers to the snow receiving bins. Upon contact with wastewater with the average annual temperature of $18^{\circ} \mathrm{C}$, snow is melting and melt water is drained back into 
the sewer, and together with wastewater is transported to the wastewater treatment facilities. Separating and crushing equipment is installed in the receiving bins for grinding snow mass and screening out coarse litter. The total free heat resources of the municipal sewer network in Moscow are estimated at 15-20 thousand Gcal/day, the heat demand for melting snow is $120-150 \mathrm{Gcal} /$ day. Thus, less than $1 \%$ of the total heat resource is required to melt all the snow removed from the streets.

Increased use of excess heat of CHP plants for this purpose seems possible, since they are the largest sources of such heat in the city. At present, snow melting installations have been operating at 4 CHP plants out of 15 functioning in the city, Fig. 4.

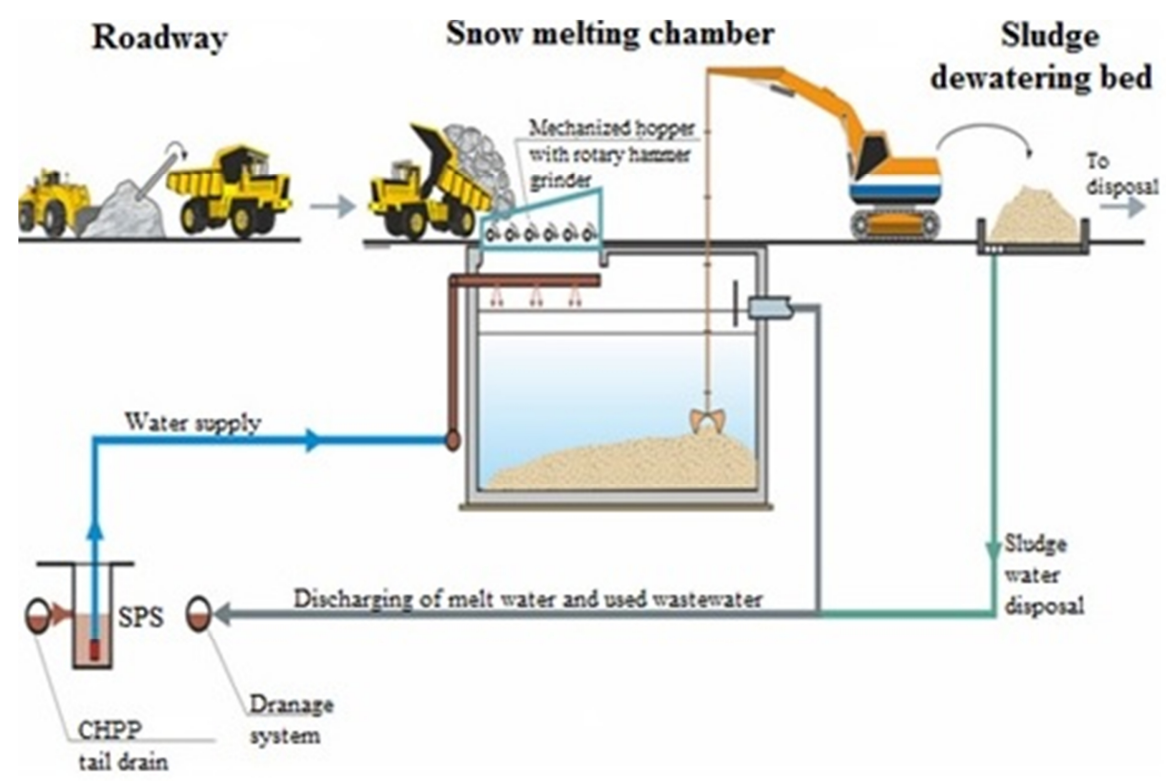

Fig. 4. Snow utilization flow scheme of a fixed-site snow-melting station at a thermal power plant

The design of snow-melting stations operating with the effluents of CHPPs is similar to the design of snow-melting stations on sewers; however, has the following specific features:

- wastewater from the snow-melting stations is discharged directly into the drainage network or into water bodies. Therefore, the level of water treatment should be higher and meet the requirements to the effluent quality in these cases;

- the temperature of wastewater varies significantly for different CHP plants and may in some cases be rather low $\left(10^{\circ} \mathrm{C}\right)$;

- the effluent used for melting snow at CHP plants is clean enough and, in some cases, can be used to blend polluted thawed snow in order to reduce its concentration to an acceptable level.

According to the data of Mosenergo, 15 large facilities in Moscow discharge warm wastewater into the sanitation system, storm sewer, into the Moskva, Krovianka, Chura Rivers.

The total volume of "waste" warm water is 518 million $\mathrm{m}^{3} /$ year (16.4 thousand $\left.1 / \mathrm{s}\right)$, of which only 61 million $\mathrm{m}^{3} /$ year ( 1.9 thousand $\mathrm{l} / \mathrm{s}$ ) is discharged into the storm sewer, 457 million $\mathrm{m}^{3} /$ year or 14.3 thousand $1 / \mathrm{s}$ is discharged into the Moskva River.

It should be noted that the General snow disposal scheme of 2002 was based on the patterns of snow cover accumulation and pollution that were calculated based on the results of snow level measurements over a period of 1946 - 1979, i.e. the data from 70 - 40 years 
ago.

The meteorological conditions that have changed in recent years in Moscow, the increase in snow depth, increased area subject to cleaning, the need to take into account the amount of snow discharged from the roofs, the new technology of cleaning streets, yards and sidewalks, the reduction in the scheduled time for snow removal, - all these factors have changed the initial data for calculating the volumes of snow subject to utilization, and required analysis and evaluation of the existing system of snow collection and disposal, and consequently, updating the General snow disposal scheme in Moscow.

In recent years, a sharp change in weather conditions in all continents, in North America, Europe and Russia is observed, and accordingly, the changes in the intensity and duration of precipitations, a multiple increase in their volumes, systematic record-breaking temperature rises, changes in typical weather conditions by months, etc. have become obvious [14].

As observations of the weather conditions in Moscow carried out by the Hydrometeorological Bureau of Moscow and the Moscow Region show, in recent years a sharp increase in both annual and daily snow depth and, accordingly, an increase in the depth of snow cover on the territory of the city and the amount of snow subject to utilization.

In the General snow disposal scheme in Moscow of 2002, $80 \mathrm{~cm}$ was taken as the design value of the average annual depth of the fallen snow layer at $80 \%$ snow probability. Based on the processed meteorological observations for recent years of the annual average snow level the updated General scheme provides for the substantiated design value of snow depth $-152 \mathrm{~cm}$ at $80 \%$ fallen snow probability - as a reference for the snow disposal system.

Currently, the area of the Moscow road facilities cleaned of snow has increased from 75 to $108 \mathrm{~km}^{2}$ - the estimated volume of snow for disposal has increased 1.52 times, accordingly the cost of collecting, transporting and disposing of snow in the city of Moscow increased.

Studies have shown that the dynamics of wastewater entry into the Moscow sanitation system from 1998 to the present indicates a steady $4-5 \%$ decrease in wastewater inflow per year. As a result, by 2020 , the average daily load on the treatment facilities decreased to $66 \%$ of the design value. Thus, the hydraulic operation conditions of the Moscow treatment facilities over the past 10-15 years have become more favorable. Opportunities for receiving additional wastewater from the suburban areas have opened up. An increase in the total volume of the received flow owing to the inflow of surface runoff and drainage effluents, as well as the expansion of the system of snow removal and disposal from the city territory is absolutely achievable. The updated General snow disposal scheme in Moscow provides for an assessment of the impact of snow-melting stations built on sewers on the operation of the municipal sewer network and Moscow wastewater treatment facilities. The calculations confirmed the possible snow discharge into the sewers; even if all the snow from the roads will be removed to the sewers its volume after melting will amount to only about $2 \%$ of the wastewater flow. And even if the effect of snow treatment at the snowmelting stations is not taken into account, an increase in the concentration of pollutants will be low. It has been established that the system of snow-melting stations on the sewer networks affects the municipal wastewater treatment facilities only in relation to one indicator - oil products.

At the Kuryanovskie wastewater treatment facilities in Moscow, the oil products load in winter period increases up to 2 times compared to summer. However, due to the good adaptation of the activated sludge at the treatment facilities, this increase in load in winter periods of the year did not entail a marked deterioration in the effluent quality in relation to either oil products or other indicators. 
It was stated that during snow processing at the snow-melting stations, a significant amount of pollutants present in snow mass is removed, in particular, oil products in the amount of 1,012.3 tons per season, suspended solids - 41,220.9 tons, iron - 866.4 tons, etc. This prevents environmental damage to the city of Moscow in winter and has a positive effect on the implementation of the industrial snow disposal system.

In the process of updating the General snow disposal scheme in Moscow, the impact of deicing chemicals on the environment, in particular on the quality of snow and soil covering, was evaluated.

An analysis of the monitoring results showed that in the last two years, the average concentrations of the deicing agents in the Moskva River did not exceed the MPC for the water bodies of cultural and social use. This is a positive result of the implementation of the General snow disposal scheme in Moscow. In general, the technical solutions adopted for the maintenance of the Moscow road facilities in winter provide for an acceptable level of environmental impact on the city water bodies.

This is largely due to the fact that in the process of snow utilization at snow-melting facilities the initial concentration of pollutants in melted snow significantly changes, and the sewer receives wastewater with grossly changed pollution indicators.

At the same time, the analysis of the snow removal and anti-icing treatment of the city pavements revealed the need to develop additional measures and approaches to the noted problems. In particular, the product line of existing domestic deicing agents does not provide for the sufficient reduction of the negative impact of chlorine and nitrogen phosphates contained in them on the environment. The number of relatively safe chemicals produced by industry is insufficient to meet the needs of the city, both in terms of amount and product line.

The above-mentioned circumstances determine the need to continue developing advanced deicing agents.

In light of the climatic changes and increase in snowfall, we have formulated proposals to enhance the operation of the snow disposal system in the city of Moscow.

A simple calculation shows that the cost of snow transportation in a city with heavy traffic is comparable to the energy costs required to melt snow mass at the place of its formation.

The use of mobile snow melters ensure exactly this mode of operation. They are delivered to the place of snow mass formation and work until they melt the required amount of snow. Then they are transported to the next place. Fig. 5.

The analysis of snow removal experience in foreign countries with climatic conditions similar to the Moscow region, such as Canada and the USA, showed that not only fixed-site but also mobile snow melters have been widely used in these countries. Their capacity ranges from 20 to 500 tons of snow per hour. They are particularly efficient in the lack of time for the transportation of snow and free space for long-term storage [15].

As the experience of operating the first purchased Canadian mobile snow melters of high capacity in Moscow showed that they can successfully supplement fixed-site snow melting stations, saving expensive land within the city, and the time to obtain land allotments and coordinated approvals while designing fixed-site snow-melting stations, as well as time and money for construction and assembly works. They do not need to be permanently connected to the utility networks.

It is the use of mobile snow melters that will largely solve the problem of snow utilization in extreme snowfalls. In future, while designing new or upgrading the existing SMSs, as well as operating small mobile snow melters, it seems appropriate to consider the possibility of feeding into them high-temperature wastewater from public bathhouses, laundries and swimming pools. Taking into account the rapid development of the municipal subway and the use of advanced means and equipment to ensure its smooth functioning, it 
would be recommended to consider the discharge of Metro wastewater in the technical calculations of the snow melting stations.

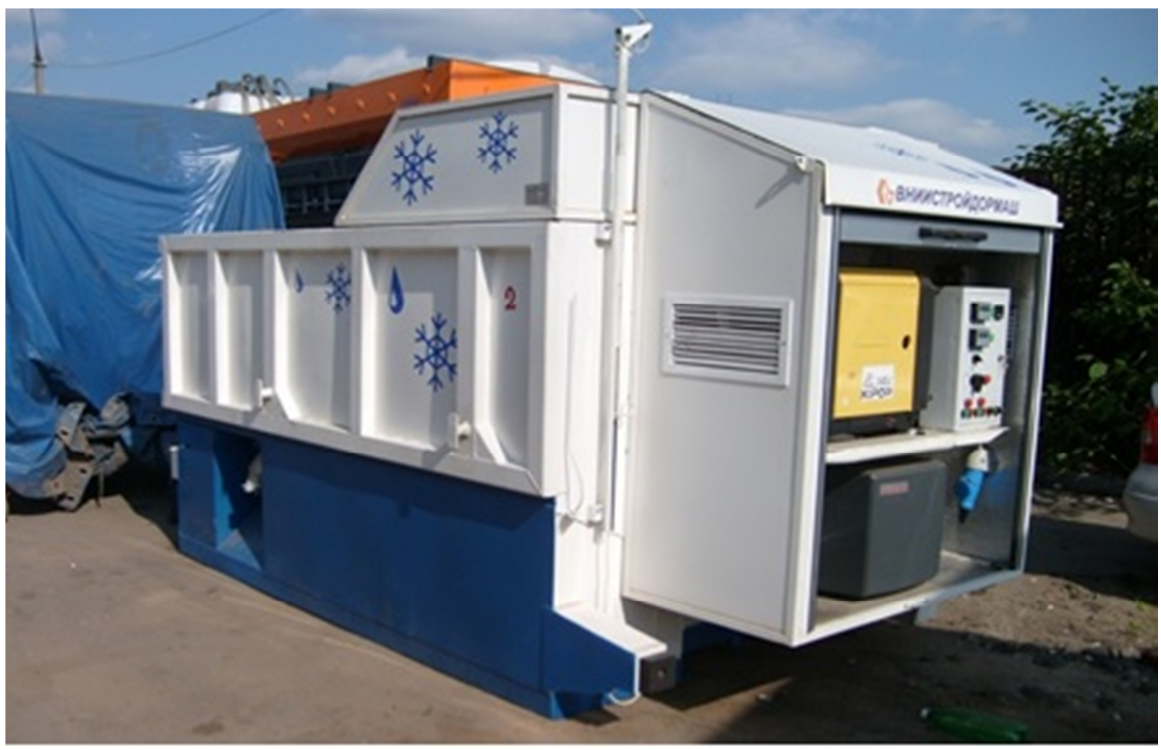

Fig. 5. Mobile snow melter STM -11

\section{Conclusions}

1. In recent years, there has been a change in climatic conditions - a sharp increase in both the annual and daily snow depth and, accordingly, increasing are the depth of snow cover on the territory of the city of Moscow and the amount of snow subject to removal and utilization.

2. The unique arrangement of industrial snow removal that does not have world analogues in scale and technical support can, providing the appropriate operation and implementation of the organizational and technical measures determined in the updated General snow disposal scheme, ensure the normal functioning of Moscow in winter and significantly reduce the environmental load on the drainage hydrographic network of the metropolis.

3. Studies have shown that the construction of new snow melting stations on sewers in Moscow (with the exception of South Butovo) is hardly possible due to the lack of sites with suitable conditions near trunk sewers. These factors and analysis of the capabilities of the existing snow collection and disposal system in Moscow showed that the focal point of updating the General snow disposal scheme is the reduction of snow utilization costs by the decentralization of snow melting facilities (reduction of the hauling distance), widespread use of mobile snow melters, and low-grade heat sources (CHPPs, bathhouses, laundries, swimming pools, industrial enterprises, Metro).

\section{References:}

1. B.E. Koretskii. Vestnik MGSU, 3, 42-46 (2007).

2. N.V. Borisiuk. Stroitel'naia Tekhnika i Tekhnologii, 1,54-58 (2012) 
3. E.I. Pupyrev et al. Environmental Engineering: encyclopedic reference book., 771-789 (2009).

4. N.V.Pavlov, V.E.Koretskii. Cleaning municipal highways in winter (2002).

5. Road Ecology of the XXI century. (Voronezh, 2000)

6. S.V. Khramenkov, A.N. Pakhomov, M.V. Bogomolov et al. Vodosnabzhenie i Sanitarnaia Tekhnika. 10, 19-22 (2008)

7. V.E. Koretskii. Environmental engineering protection of the water system of the northern metropolis in winter. Proceedings of the $7^{\text {th }}$ International Congress "Water: Ecology and Technology - ECWATECH-2006”, 23-28 (2006).

8. V. Vorobyov, A. Manakov, A. Reger, I. Tanaino, MATEC Web of Conferences 216, 02009 (2018). DOI: 10.1051/matecconf/201821602009

9. A.N. Mirnyi, L.S. Skvortsov, E.I.Pupyrev, V.E.Koretskii. Municipal Ecology. Encyclopedic Guide. 128, (2016).

10. General snow disposal scheme in Moscow. Order of the Moscow Government Premiere of 04.25.2002 No. 408-RP "On Approval of the Target Comprehensive Program for the Organization of Dry Snow Dumps, Snow-Melting Chambers and Snow Melters in Accordance with Environmental Requirements of 2001-2003."

11. A.M. Zemtsova, N.A. Evstigneeva. Uspekhi Sovremennogo Estestvoznaniia, 7, 113113 (2015).

12. A.S. Shelomkov, T.A. Shchigal. Engineering systems and water use optimization, 2, 75 -77 (2002)

13. B.A. Adamovich, Ekologiia i Promyshlennost' Rossii, 1, 18-21, (2006)

14. I.B. Kilkis, ASHRAE Transactions, 100 (1), 434-441, (2014)

15. T. Hiroshi, T. Nobuhiro, K. Nobuo. Development of Highway Snow Melting Technology Using Natural Energy, Proceedings of the 10th PIARC International Winter Road Congress, Sweden (1998) 